Brit. F. industr. Med., 1966, 23, 133

\title{
Absorption and Excretion of Diquat and Paraquat in Rats
}

\author{
J. W. DANIEL and J. C. GAGE \\ From Imperial Chemical Industries Limited, Industrial Hygiene Research Laboratories, \\ Alderley Park, Cheshire
}

The fate of ${ }^{14} \mathrm{C}$-labelled diquat and paraquat after oral and subcutaneous administration of single doses has been studied in the rat. By both routes of administration the radioactivity usually appears in the excreta within two days. In a few cases a small amount is excreted in the urine on the third day or in faeces on the fourth day. After an oral dose of paraquat no radioactivity could be detected in bile, and with diquat less than $5 \%$ of the dose appeared in bile within 24 hours. Both diquat and paraquat are poorly absorbed from the gut, and after subcutaneous administration little or none appears in faeces.

By comparison of the measurements of radioactivity with a specific chemical test for diquat and paraquat, the presence of a small amount of metabolites in the urine after oral dosing has been detected. As no such metabolism has been observed after subcutaneous administration it seems probable that there is some absorption of degradation products formed within the gut. It has been shown that about $70 \%$ of an oral dose of diquat and about $30 \%$ of a dose of paraquat is present in faeces as metabolic products. In vitro experiments have shown that this is probably due to microbiological degradation in the gut.

Diquat and paraquat are bipyridilium compounds which have been developed as herbicides and desiccants under the trade names 'Reglone' and 'Gramoxone' respectively (Calderbank and Crowdy, 1962). Their structural formulae are indicated below; they are usually supplied as the dichloride, dibromide or dimethosulphate salts. Both can be reduced to coloured free-radicals, and paraquat has been known for many years as the oxidation-reduction indicator methyl viologen.

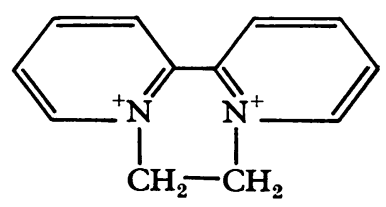

diquat

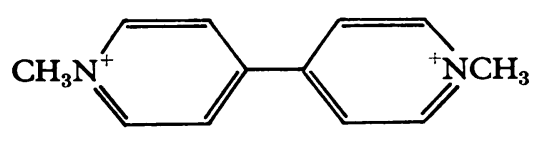

paraquat
Although in most of the agricultural applications of these substances there is no contamination of food for human or animal consumption, such residues may occur in certain more limited usages (Calderbank, Morgan, and Yuen, 196I ; Calderbank and Yuen, 1965). Diquat and paraquat are being subjected to an extensive toxicological investigation in these laboratories, part of which is being published in the present issue of this Journal (Clark, McElligott, and Hurst, 1966). A study of their fate after administration to the rat has been undertaken in order to throw light on the difference which has been observed between their oral and parenteral toxicities, and also to ascertain to what extent they are metabolized in the body.

\section{Materials and Methods}

Diquat dibromide labelled with ${ }^{14} \mathrm{C}$ on the ethylene bridge $(0.93 \mathrm{mc} . / \mathrm{mM}$.) was obtained from Plant Protection Ltd. Diquat dichloride was prepared by passing a solution of the labelled dibromide through a column of Deacidite FF (chloride form) and crystallizing the product from aqueous ethanol to give white needles of the monohydrate. Paraquat dichloride labelled with ${ }^{14} \mathrm{C}$ in the methyl groups $(0.94 \mathrm{mc}$. $/ \mathrm{mM}$.) was also obtained from Plant Protection Ltd. Labelled paraquat dimethosulphate was prepared by treating the dichloride with aqueous silver methosulphate and crystallizing the product from ethanol.

Received for publication September 14, 1965. 
Albino Wistar rats, male unless otherwise indicated and weighing between 200 and $230 \mathrm{~g}$., were used in this investigation. Apart from those used for the experiments included in the first part of Table $I$, which were purchased from A. Tuck Ltd., the rats were from the Alderley Park SPF colony. The rats were dosed with aqueous solutions of the labelled diquat or paraquat salts by gastric intubation or by subcutaneous injection; none of the doses exceeded the $\mathrm{LD}_{50}$ value and they were not attended by obvious toxic effects. The dosing solutions were assayed by the radiochemical and chemical methods described below. The dosed rats were placed in individual metabolism cages fitted with urine and faeces collectors (Gage, r96I), cooled with solid carbon dioxide, and protected from light. These precautions were necessary as otherwise chemical analysis revealed a progressive loss of diquat and paraquat from the urine, due presumably to bacterial degradation.

For the collection of bile a fine polythene cannula was inserted into the bile duct under sodium pentobarbital (Nembutal, Abbot) anaesthesia. Rats were maintained in a restraining cage for 24 hours and provided with drinking-water containing isotonic saline and $\mathrm{I} \%$ glucose.

Analysis of Urine Urine was rapidly thawed, washed from the separator, and diluted to $50 \mathrm{ml}$. with water. After the addition of $12.5 \mathrm{ml} .25 \%$ trichloroacetic acid the solution was centrifuged; the precipitate was re-suspended in $6 \mathrm{ml} .5 \%$ trichloroacetic acid and centrifuged; and the two supernatants were mixed. No loss of radioactivity on the precipitate occurred at this stage. A portion of this solution, equivalent to a count in the region of 50 c.p.s., was added to $10 \mathrm{ml}$. scintillator solution (50.2 g. naphthalene; $5.0 \mathrm{~g}$. PPO; 0.125 g. POPOP in $500 \mathrm{ml}$. $p$-dioxan) in screw-capped glass vials treated internally with Repelcote (Hopkin and Williams Ltd.); this treatment prevented a progressive loss of counts due presumably to absorption of radioactive substance on the glass surface. The same volume of trichloroacetic supernatant, spiked with a suitable amount of labelled diquat or paraquat, was counted for the determination of efficiency. Counts were made for IOO sec. with a liquid measuring head 2022, coincidence control unit 2032, and scaler I700 (Isotope Developments Ltd.). Bile was counted in a similar manner after dilution with water.

The colorimetric determination of diquat and paraquat was based on the methods described by Calderbank et al. (I96I) and Calderbank and Yuen (1965).

Diquat A column (10 $\mathrm{mm}$. internal diameter) was prepared from I ml. Dow AG-50W-X8 cation exchange resin. The column was washed with water, then with $25 \mathrm{ml}$. $6 \mathrm{M}$ sodium chloride solution to convert the resin to the sodium form, and then with $25 \mathrm{ml}$. water. A portion of the trichloroacetic supernatant was passed through the column at a rate of 3 to $4 \mathrm{ml}$./minute. The column was then washed successively with $25 \mathrm{ml}$. portions of water, $0.6 \mathrm{M}$ sodium chloride, and water. The diquat was eluted from the column with $25 \mathrm{ml}$. $5 \mathrm{M}$ ammonium chloride solution at a rate not exceeding
$0.5 \mathrm{ml} . / \mathrm{min}$.; I ml. of a freshly prepared $0.2 \% \mathrm{w} / \mathrm{v}$ solution of sodium dithionite in $5 \%$ aqueous sodium tetraborate was added to a $5 \mathrm{ml}$. eluate, and the optical density was measured in I cm. cells at $379 \mathrm{~m} \mu$. For strong diquat solutions a smaller volume of eluate was taken and diluted to $5 \mathrm{ml}$. with $5 \mathrm{M}$ ammonium chloride; for weak solutions the volumes were doubled and the optical density was measured in $4 \mathrm{~cm}$. cells.

Paraquat A column was prepared from the same resin, washed with water but left in the hydrogen form. After passage of the trichloroacetic supernatant through the column, it was washed with $25 \mathrm{ml}$. water and then eluted with $25 \mathrm{ml}$. $5 \mathrm{M}$ ammonium chloride. The colour was developed with $0.2 \%$ sodium dithionite in $\mathrm{N}$ sodium hydroxide solution, and the optical density was measured at $600 \mathrm{~m} \mu$.

Standard curves prepared by submitting known amounts of diquat and paraquat to this colour development procedure were linear, the lower limit of sensitivity for diquat being $3 \mu \mathrm{g}$. and for paraquat to $\mu \mathrm{g}$.

Analysis of Faeces For the determination of the faecal excretion of radioactivity the daily output of faeces was weighed and a $10 \% \mathrm{w} / \mathrm{v}$ homogenate in water was prepared. A 2-ml. portion of the homogenate was oxidized with Van Slyke acid, and the carbon dioxide liberated was trapped in sodium hydroxide solution (Daniel and Gage, 1965). A 2-ml. portion from each absorber was transferred to a glass vial, and $13.5 \mathrm{ml}$. of the scintillator solution mentioned above, containing $4 \%$ colloidal silica (B.D.H. low in iron), was added. The vial was capped and shaken to induce gelling. For the determination of counting efficiency, $0.1 \mathrm{ml}$. of a $\left[{ }^{14} \mathrm{C}\right]$ sodium carbonate solution (I43 c.p.s.) was added to a 2-ml. portion of the absorber solution and treated as above.

For the determination of the extent of metabolism in the faeces, the homogenate, after samples had been taken for radioactivity measurements, was precipitated by the addition of trichloroacetic acid to give a final concentration of $5 \% \mathrm{w} / \mathrm{v}$. The suspension was centrifuged, the precipitate was washed twice with $5 \%$ trichloroacetic acid, and the supernatant and washings were mixed. The solution was then analysed colorimetrically for diquat or paraquat by the methods described above for urine. By the analysis of a homogenate of normal faeces to which had been added known amounts of diquat or paraquat it was shown that this procedure gave satisfactory recoveries. The mixture obtained after the in vitro incubation of diquat and paraquat with faecal homogenates was analysed in a similar manner.

\section{Results and Discussion}

The results in Table $I$ show that in most experiments the radioactivity of $\left[{ }^{14} \mathrm{C}\right]$ diquat and paraquat, administered as a single oral dose, appeared in the excreta within two days. Occasionally some was found on the third day and, when the excretion of faeces was delayed, on the fourth 
TABLE I

Excretion of Radioactivity (eXpressed as Percentage of Dose Administered) by Rats Dosed

\begin{tabular}{|c|c|c|c|c|c|c|c|c|c|}
\hline \multirow{3}{*}{\multicolumn{2}{|c|}{ Compound }} & \multirow{3}{*}{$\begin{array}{l}\text { Dose } \\
\text { (mg./kg.) }\end{array}$} & TH ${ }^{2} \mathrm{C}-\mathrm{LABELL}$ & DIQUAT & PARA & & & & \multirow{3}{*}{$\begin{array}{l}\text { Total } \\
\text { Excretion }(\%)\end{array}$} \\
\hline & & & \multirow[t]{2}{*}{ Route } & \multicolumn{5}{|c|}{ Daily Excretion (\%) } & \\
\hline & & & & Day & $\mathbf{I}$ & 2 & 3 & 4 & \\
\hline \multirow[t]{18}{*}{ (A) } & Diquat dibromide & 5 & Oral & Urine & $\circ$ & 4 & 0 & - & 4 \\
\hline & & & & Faeces & 7 & 90 & 0 & 一 & \\
\hline & & Io & Oral & Urine & 5 & I & 0 & - & 6 \\
\hline & & & & Faeces & 80 & IO & 0 & - & \\
\hline & & 5 & Subcutaneous & Urine & 94 & 4 & $\circ$ & - & 98 \\
\hline & & & & Faeces & 0 & 0 & 一 & 一 & \\
\hline & & 6 & Subcutaneous & Urine & 84 & 3 & $\mathbf{I}$ & o & 88 \\
\hline & & & & Faeces & 2 & 0 & 一 & - & \\
\hline & & 6 & Subcutaneous & Urine & 89 & 4 & $\circ$ & - & 93 \\
\hline & & & & Faeces & 0 & 0 & - & - & 93 \\
\hline & Diquat dichloride & 22 & Oral & Urine & 7 & 2 & 0 & 0 & 9 \\
\hline & & & & Faeces & 13 & 57 & 14 & 0 & 84 \\
\hline & & 24 & Oral & Urine & 8 & 2 & I & 0 & II \\
\hline & & & & Faeces & 8 & 44 & 38 & 0 & $90\}$ \\
\hline & Paraquat dichloride & 4 & Oral & Urine & 5 & I & 0 & - & 6\{ \\
\hline & & & & Faeces & 75 & 20 & $\mathbf{I}$ & 0 & $96\}$ \\
\hline & & 6 & Oral & Urine & 5 & 0.6 & 0 & 一 & $6\}$ \\
\hline & & & & Faeces & 38 & 51 & 4 & 0 & $93\}$ \\
\hline \multirow[t]{12}{*}{ (B) } & Paraquat dimethosulphate & $2 \cdot 5$ & Oral & Urine & $16 \cdot 0$ & $2 \cdot 0$ & 0.7 & 0.4 & \\
\hline & & & & Faeces & $3 \cdot 7$ & $\circ$ & $66 \cdot 0$ & $16 \cdot 0$ & 85.7 \\
\hline & & 24 & Oral & Urine & $16 \cdot 2$ & $5 \cdot 1$ & $I \cdot O$ & 0.6 & $22 \cdot 9$ \\
\hline & & & & Faeces & $16 \cdot 5$ & $19 \cdot 0$ & $30 \cdot 0$ & $3 \cdot 0$ & $68 \cdot 5$ \\
\hline & & $24^{\star}$ & Oral & Urine & $12 \cdot 6$ & $3 \cdot 3$ & 0.5 & 0 & $16 \cdot 4$ \\
\hline & & & & Faeces & $17 \cdot 0$ & $63 \cdot 6$ & 0.4 & 0 & $81 \cdot 0$ \\
\hline & & $24^{\star}$ & Oral & Urine & 16.0 & $4 \cdot 2$ & 0.6 & $\circ$ & $20 \cdot 8$ \\
\hline & & & & Faeces & 0 & $54 \cdot 0$ & $19 \cdot 0$ & $3 \cdot 8$ & $76 \cdot 8$ \\
\hline & & $23^{\star}$ & Subcutaneous & Urine & $93 \cdot 0$ & $2 \cdot 0$ & $\mathbf{I} \cdot \mathbf{I}$ & 0 & $96 \cdot I$ \\
\hline & & & & Faeces & $8 \cdot 5$ & $6 \cdot 5$ & 0.7 & 0 & $15.7\}$ \\
\hline & & $2 I^{\star}$ & Subcutaneous & Urine & $69 \cdot 5$ & $2 \cdot 2$ & $1 \cdot 3$ & 0 & $73.0\} 87$ \\
\hline & & & & Faeces & 10.5 & $2 \cdot 4$ & $1 \cdot 3$ & 0 & $14 \cdot 2\}^{87}$ \\
\hline
\end{tabular}

^Female rats. (A) Rats from A. Tuck Ltd. (B) Alderley Park SPF rats.

day also. The percentage of the dose appearing in the urine seems to depend on the strain of rat used; in the first part of Table I the urinary excretion did not exceed $11 \%$, whereas in the second part of this Table and in Table II double this figure was reached. With both diquat and paraquat the bulk of an oral dose was found in the faeces, whereas after a subcutaneous dose most was in the urine and little or none in the faeces. This, together with the absence of any marked biliary excretion (Table III), is strong evidence that diquat and paraquat are poorly absorbed from the gut, and can account for the difference which has been observed between their oral and parenteral toxicities. The poor absorption of diquat and paraquat is in line with the observations of Schanker, Tocco, Brodie, and Hogben (1958) that the cations of strong bases are very slowly absorbed from rat small intestine. As might be expected, the results in Tables I and II give no indication that the nature of the anion influences absorption and excretion.

Table II shows that the percentage excretion of an oral dose in the urine calculated from a chemical analysis was slightly lower than that obtained from radioactivity measurements; the differences are significant and indicate that a proportion of the dose appeared in the urine in a form other than diquat or paraquat, though there is insufficient information to calculate the confidence limits of these differences. It does not necessarily follow from this that there was some metabolism of absorbed diquat and paraquat, since after subcutaneous dosing an analysis of the urine by the colorimetric and radioactivity methods gave results which agree closely (Table IV). It is more likely that after oral dosing there was some systemic absorption of the degradation products which were produced in the gut. A comparison of the colorimetric and radioactivity determinations on faeces shown in Table $\mathrm{V}$ indicates that about $70 \%$ of an oral dose of diquat, and about $30 \%$ of a dose of paraquat, appeared in the faeces in a degraded form. Table VI provides evidence that this degradation was due to microbiological actionin vitro incubation of diquat and paraquat with a 
TABLE II

Analysis of Urine from Rats Dosed Orally with Diquat and Paraquat, using Colorimetric Assay AND RADIOACTIVITY MEASUREMENTS

\begin{tabular}{|c|c|c|c|c|c|c|c|c|}
\hline \multirow[t]{3}{*}{ Compound } & \multirow{3}{*}{$\begin{array}{l}\text { Dose } \\
\text { (mg./kg.) }\end{array}$} & \multicolumn{4}{|c|}{$\%$ Dose Excreted Daily } & \multicolumn{3}{|c|}{$\%$ Dose Metabolized } \\
\hline & & \multicolumn{2}{|c|}{ Radioactivity } & \multicolumn{2}{|c|}{ Colorimetry } & \multirow[b]{2}{*}{$\mathbf{I}$} & \multirow[b]{2}{*}{2} & \multirow[b]{2}{*}{ Total } \\
\hline & & Day I & 2 & I & 2 & & & \\
\hline \multirow[t]{5}{*}{ Diquat dibromide } & $20 \cdot 5$ & $6 \cdot 7$ & $\mathrm{I} \cdot 8$ & $6 \cdot 2$ & $2 \cdot 2$ & 0.5 & 一 & 0.5 \\
\hline & $22 \cdot 5$ & $6 \cdot 2$ & 一 & $5 \cdot 4$ & - & 0.8 & 一 & 0.8 \\
\hline & $21 \cdot 5$ & $5 \cdot 0$ & $1 \cdot 3$ & $4 \cdot 6$ & $I \cdot I$ & 0.4 & 0.2 & 0.6 \\
\hline & 85 & $9 \cdot 8$ & $4 \cdot 3$ & $7 \cdot 8$ & $2 \cdot 9$ & $2 \cdot 0$ & $1 \cdot 4$ & $3 \cdot 4$ \\
\hline & 85 & $7 \cdot 8$ & $11 \cdot 6$ & 5.4 & $8 \cdot 6$ & $2 \cdot 4$ & $3 \cdot 0$ & 5.4 \\
\hline \multirow[t]{3}{*}{ Paraquat dichloride } & 50 & $5 \cdot 7$ & $8 \cdot 6$ & $5 \cdot 2$ & $7 \cdot 3$ & 0.5 & $1 \cdot 3$ & $1 \cdot 8$ \\
\hline & 50 & $5 \cdot 2$ & 3.4 & 4.5 & $2 \cdot 9$ & 0.7 & 0.5 & $\mathbf{I} \cdot \mathbf{2}$ \\
\hline & 50 & $8 \cdot 4$ & $4 \cdot 3$ & $7 \cdot 0$ & $3 \cdot 6$ & $1 \cdot 4$ & 0.7 & $2 \cdot \mathbf{I}$ \\
\hline \multirow[t]{3}{*}{ Paraquat dimethosulphate } & 22 & $16 \cdot 3$ & $5 \cdot 2$ & $12 \cdot I$ & $4 \cdot 3$ & $4 \cdot 2$ & 0.9 & $5 \cdot 1$ \\
\hline & 22 & $16 \cdot 2$ & $5 \cdot 1$ & II $\cdot 8$ & $5 \cdot 2$ & 4.4 & 0 & 4.4 \\
\hline & 22 & 14.2 & $1 \cdot 8$ & $12 \cdot 6$ & $\mathrm{I} \cdot 7$ & $1 \cdot 6$ & 0.1 & $\mathrm{I} \cdot 7$ \\
\hline
\end{tabular}

TABLE III

BILIARY EXCRETION OF RADIOACTIVITY BY RATS DOSED ORALIY WITH $\left[{ }^{14} \mathrm{C}\right]$ DIQUat and Paraquat

Dose Radioactivity Excreted in

(mg./kg.) Bile in 24 hrs. (\%)

\begin{tabular}{lcl}
\hline Diquat dibromide & I.2 & I.I \\
& I.2 & $4 \cdot 8$ \\
& 64 & $1 \cdot 3$ \\
& 64 & $1 \cdot 7$ \\
Paraquat dichloride & 0.5 & 0 \\
& 0.5 & 0 \\
& 0.5 & 0
\end{tabular}

TABLE IV

ANALYSIS OF 24-HOUR URINE FROM RATS DOSED SUBCUtankously With DiQuat and Paraquat, using

Colorimetric ASSAY aND RAdIOACTIVITY MEASUREMENTS

Compound Dose Percentage of Dose Excreted

\begin{tabular}{llcc} 
& $(\mathrm{mg} . / \mathrm{kg})$. & & \\
\cline { 3 - 4 } & & Radioactivity & Colorimetry \\
\hline Diquat dichloride & 24 & 89 & 90 \\
& 24 & 81 & 81 \\
& 25 & 84 & 83 \\
Paraquat dichloride & 31 & 87 & 85 \\
& 13.2 & 80.5 & 79.5 \\
& 12.5 & 98 & 96 \\
& 12.5 & 83.5 & 88.5
\end{tabular}

TABLE V

ANALYSIS BY Radioactivity aNd Colorimetric METhods of Faeces from Rats Dosed Orally with 0.7 Mg./Kg. $\left[{ }^{14} \mathrm{C}\right]$ Diquat and Paraquat. Results of Duplicate EXPERIMENTS

Percentage of Dose in Faeces

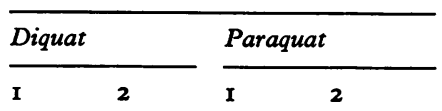

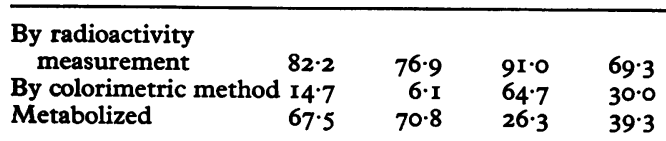

TABLE VI

In vitro Destruction of Diquat and PaRaquat by Faecal. HOMOGENATES

Diquat or paraquat was added to $10 \mathrm{ml}$. of a $20 \%$ homogenate of the contents of rat caecum either (A) fresh, or (B) heated in a boiling water-bath for 3 minutes. Mixture was incubated at $37^{\circ} \mathrm{C}$. and then analysed.

\begin{tabular}{|c|c|c|c|c|c|c|}
\hline & \multirow{2}{*}{$\begin{array}{l}\text { Incubation } \\
\text { Period } \\
\text { (hrs.) }\end{array}$} & \multicolumn{2}{|c|}{ Diquat $(\mu g)}$. & \multicolumn{2}{|c|}{ Paraquat ( $\mu g)}$. & \multirow[t]{2}{*}{$\%$ Loss } \\
\hline & & Added & Found & Added & Found & \\
\hline & $2 I$ & & & 583 & 365 & 38 \\
\hline A & 69 & & & 583 & 330 & 43 \\
\hline B & $2 I$ & & & 583 & 558 & 4 \\
\hline B & 69 & & & 583 & 518 & II \\
\hline A & 24 & 100 & 48 & & & 52 \\
\hline B & 24 & 100 & 92 & & & 8 \\
\hline
\end{tabular}

faecal homogenate resulted in 40 to $50 \%$ destruction within 24 hours, whereas a similar experiment using a faecal homogenate which had been subjected to. previous heat treatment produced only a minor loss of diquat and paraquat in this period.

Technical assistance was provided by Pamela Gorham and Marguerite Youngs.

REFERENCES

Calderbank, A., and Crowdy, S. H. (1962). Rep. Prog. Appl. Chem., 47, 536.

—, Morgan, C. B., and Yuen, S. H. (196I). Analyst, 86, 569.

- and Yuen, S. H. (1965). Ibid., 90, 99.

Clark, D. G., McElligott, T. F., and Hurst, E. W. (1966) Brit. F. industr. Med., 23, 126.

Daniel, J. W., and Gage, J. C. (1965). Food Cosmet. Toxicol., 3, 405 .

Gage, J. C. (196r). Brit. F. industr. Med., 18, 287.

Schanker, L. S., Tocco, D. J., Brodie, B. B., and Hogben, C. A. M. (1958). F. Pharmacol. exp. Ther., 123, 81. 